\title{
Analisis Zat Pemanis Sakarin dan Siklamat Pada Minuman Bubble Drink yang Dijual di Kota Surakarta
}

\section{Determination of Saccarine and Cyclamate in Bubble Drink Sold in Surakarta}

\author{
Wimpy $^{1}$, Tri Harningsih ${ }^{2}$, Tatiana Siska Wardani ${ }^{3}$ \\ wimpy@stikesnas.ac.id \\ 1,2Program Studi D-III Teknologi Laboratorium Medis, Sekolah Tinggi Ilmu Kesehatan Nasional \\ ${ }^{3}$ Program Studi S 1-Farmasi, Fakultas Ilmu Kesehatan, Universitas Duta Bangsa Surakarta
}

\begin{abstract}
Abstrak
Zat pemanis ini merupakan suatu senyawa yang secara sengaja ditambahkan dan digunakan untuk meningkatkan cita rasa dan aroma, memperbaiki sifat-sifat fisik, sebagai pegawet, memperbaiki sifat-sifat kimia dan sumber kalori bagi tubuh. Zat pemanis ada dua jenis yaitu pemanis alami dan pemanis buatan. Produsen minuman dan pangan seperti produsen bubble drink lebih memilih untuk menggunakan pemanis buatan dibandingkan pemanis alami karena harga lebih murah dan tingkat kemanisan pemanis buatan lebih tinggi dibandingkan pemanis alami. Pemanis buatan seperti sakarin dan siklamat jika dikonsumsi secara berlebih dapat memicu terjadinya gangguan kesehatan seperti penyakit saraf, hipertensi, dan kanker otak.Jenis penelitian adalah ekperimental dengan purposive sampling. 25 sampel diperoleh dari penjual bubble drink yang berada di 5 kecamatan yang dijual di kota Surakarta. Tempat penelitian dilaksanakan di Laboratorium Kimia STIKES Nasional. Uji kualitatif yang digunakan menggunakan rapid test kit sakarin dan siklamat. Hasil uji kualitatif pada 25 sampel menggunakan rapid test kit menunjukkkan hasil negatif, tidak ditemukan adanya pemanis sakarin dan siklamat.

Kata Kunci : bubble drink, rapid test kit, sakarin, siklamat.
\end{abstract}

\begin{abstract}
Sweetener known as a compound that is intentionally added and used to improve it's taste and aroma, it also used to improve physical and chemical properties. It also used as the source of calories for the body. There are two types of sweetener: natural sweeteners and artificial sweeteners. Beverage and food producers such as bubble drink producer prefer to use artificial sweeteners rather than natural sweeteners because it is cheaper and sweeter than natural sweeteners. If we use excessive amounts of saccharin and cyclamate, they can lead to many health problems such as neurological diseases, hypertension, and brain cancer.This is an experimental research with purposive sampling method. Samples were collected from bubble drink sellers in 5 sub-districts of the Surakarta City. The experiment was conducted at the National STIKES Chemistry Laboratory. Saccharin and cyclamate were determined by rapid test kits. Qualitative test results on 25 buble drinks did not show the presence of saccharin and cyclamate sweetener.
\end{abstract}

Keywords : bubble drink ,rapid test kit, saccharine, cyclamate. 


\section{Pendahuluan}

Penggunaan bahan tambahan pada makanan dan minuman sering ditemui dalam kehidupan sehari- hari. Bahan tambahan tersebut sengaja digunakan karena dengan tujuan memiliki kualitas yang lebih baik. Bahan tambahan makanan atau minuman yang sering ditemukan adalah pewarna, pengawet, pengental, dan pemanis (BPOM, 2014)

Pemanis buatan adalah bahan tambahan pangan yang dapat menyebabkan rasa manis pada produk makanan yang tidak atau sedikit mempunyai nilai gizi atau kalori, hanya boleh ditambahkan ke dalam produk makanan dalam jumlah tertentu. Menurut BPOM pemanis buatan yang dizinkan untuk dikonsumsi dengan batasan tertentu yaitu asesulfam-K (acesulfame potassium), aspartam (aspartame), siklamat (cyclamates), sakarin (saccharins), sukralosa (sucralosel trichloro galactosucrose), dan neotam (neotame) (BPOM, 2014). Takaran maksimun untuk penggunaan pemanis buatan sakarin yaitu 80$300 \mathrm{mg} / \mathrm{kg}$ berat badan, sedangkan siklamat yaitu 200-2000 mg/kg berat badan (BPOM, 2014).

Produsen minuman dan pangan lebih memilih untuk menggunakan pemanis buatan dibandingkan pemanis alami karena harga lebih murah dan tingkat kemanisan pemanis buatan lebih tinggi dibandingkan pemanis alami(Ramadhani dkk., 2018), tidak terlepas salah satunya adalah bubble drink. Penggunaan pemanis buatan yang melebihi batas aman yang dizinkan akan memicu berbagai masalah kesehatan.

Berdasarkan hasil penelitian yang dilakukan Ucar \& Yilmaz pada tahun 2015, natrium sakarin bersifat karsinogenik dan menyebabkan kematian pada tikus (Uçar \& Yilmaz, 2015). Hal ini sejalan dengan hasil penelitian Das Neves, dkk pada tahun 2010 yang menunjukkan bahwa penggunaan pemanis buatan sakarin dapat menyebabkan tumor ginjal pada tikus, dan berpotensi menyebabkan kanker pada manusia (Das Neves dkk., 2020)

Hasil penelitian Lestari (2011) mengungkapkan bahwa penggunaan pemanis buatan siklamat dapat menyebabkan beberapa gangguan kesehatan diantaranya tremor (penyakit syaraf), migrain, sakit kepala, kehilangan daya ingat, insomnia, iritasi, asma, hipertensi, diare, sakit perut, alergi, impotensi, gangguan seksual, kebotakan, dan kanker otak.(Lestari, 2011).

Natrium sakarin setelah dikonsumsi akan dikeluarkan dari tubuh dalam bentuk utuh, namun ada residu yang masih tertinggal di dalam tubuh Tubuh tidak mampu memetabolisme residu sakarin, sehingga semakin lama akan mengalami penumpukan dalam tubuh dan mampu menjadi sesuatu yang sangat berbahaya bagi tubuh (Lestari, 2011).Berdasarkan alasan tersebut penggunaan natrium sakarin dan natrium siklamat dilarang dalam dalam diet food and beverage (Winarno, 1997). Berdasarkan pada permasalahan tersebut, maka perlu dilakukan analisis zat pemanis sakarin dan siklamat pada minuman bubble drink yang dijual di kota Surakarta.

\section{Metode Penelitian}

Metode penelitian ini merupakan penelitian deskriptif dengan purposive sampling, hasil dari analisis data disajikan dalam bentuk tabel tanpa pengolahan data menggunakan aplikasi pihak ketiga.

Alat

Alat yang digunakan pada penelitian ini adalah rapid test kit sakarin dan rapid test kit siklamat dengan merk "Labstes Reagent" seperti tersaji pada gambar 1 dan 2 .

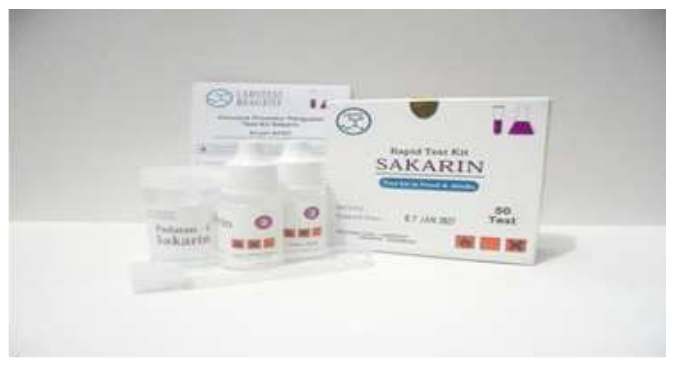

Gambar 1. Rapid Test Kit Sakarin

(www.labstteskit.com)

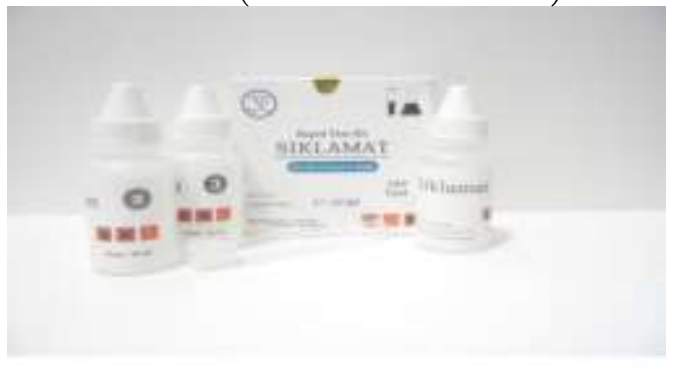

Gambar 2. Rapid Test Kit Siklamat

(www.labstteskit.com) 


\section{Bahan}

Sampel yang digunakan adalah 25 sampel minuman bubble drink yang dibeli dari penjual minuman bubble drink pada 5 kecamatan di Kota Surakarta yaitu kecamatan yaitu : Banjarsari, Jebres, Laweyan, Serengan dan Pasar Kliwon. Kriteria warna sampel adalah minuman bubble drink yang mempunyai warna cerah dan tidak terlalu tua. Sodium sakarin dan sodium siklamat menggunakan merek cap tiga tebu yang diproduksi PT Foomaco.

\section{Tahapan Penelitian}

Langkah penelitian yang ditempuh

1. Tahap Mengumpulkan Sampel.

Sampel adalah minuman bubble drink yang mempunyai warna cerah dan tidak terlalu tua dibeli dari 25 outlet yang berjualan pada 5 kecamatan kecamatan di Kota Surakarta yaitu : Banjarsari, Jebres, Laweyan, Serengan dan Pasar Kliwon.

\section{Tahap Ektraksi dengan corong pisah}

$25 \mathrm{~mL}$ sampel dipipet dan dimasukkan ke dalam corong pisah, kemudian ditambahkan $1 \mathrm{~mL} \mathrm{HCl} 2 \mathrm{~N}$ dan dilakukan ekstraksi hingga terbentuk 2 lapisan. Kita pisahkah larutan eter dan dipekatkan di cawan penguap (Tahir \& Vitrianty, 2013).

\section{Tahap Uji Kualitatif Dengan Rapid Test Kit Sakarin}

a. Pembuatan kontrol positif sakarin.

1) Larutkan 25 gram natrium sakarin dalam $50 \mathrm{~mL}$ aquadest hangat.

2) Pipet $1 \mathrm{~mL}$ larutan tersebut dan masukkan ke dalam tabung reaksi.

3) Tambahkan 3 tetes reagen sakariin 1 dan dihomogenkan.

4) Tambahkan 3 tetes reagen sakarin 2 dan dihomogenkan.

5) Panaskan dengan api kecil hingga tebentuk warna cokelat.

6) Tambahkan 3 tetes reagen sakarin 3, dan dihomogenkan.

7) Amati perubahan yang terbentuk.

Hasil positif: terbentuk warna hijau fluoresensi

b. Pembuatan kontrol negatif.

Kontrol negatif dilakukan dengan urutan langkah yang sama dengan tanpa penambahan natrium sakarin Hasil negatif : tidak terjadi perubahan c. Pemeriksaan sakarin.

1) Pipet $1 \mathrm{~mL}$ ekstrak sampel dan masukkan ke dalam tabung reaksi.

2) Tambahkan 3 tetes reagen sakariin 1 dan dihomogenkan.

3) Tambahkan 3 tetes reagen sakarin 2 dan dihomogenkan.

4) Panaskan dengan api kecil hingga tebentuk warna cokelat.

5) Tambahkan 3 tetes reagen sakarin 3 , dan dihomogenkan.

4 Tahap Uji Kualitatif Dengan Rapid Test Kit Siklamat

a. Pembuatan kontrol positif Siklamat

1) Larutkan 25 gram natrium siklamat dalam $50 \mathrm{~mL}$ aquadest hangat.

2) Pipet $1 \mathrm{~mL}$ larutan tersebut dan masukkan ke dalam tabung reaksi.

3) Tambahkan 3 tetes reagen siklamat 1 dan dihomogenkan.

4) Tambahkan 3 tetes reagen siklamat 2 dan dihomogenkan.

5) Tambahkan 3 tetes reagen siklamat 3 , dan dihomogenkan.

6) Amati perubahan yang terbentuk.

Hasil positif: terbentuk endapan abuabu.

b. Pembuatan kontrol negatif.

Kontrol negatif dilakukan dengan urutan langkah yang sama dengan tanpa penambahan natrium sakarin

Hasil negatif : tidak terjadi perubahan

c. Pemeriksaan siklamat.

1) Pipet $1 \mathrm{~mL}$ ekstrak dan masukkan ke dalam tabung reaksi.

2) Tambahkan 3 tetes reagen siklamat 1 dan dihomogenkan.

3) Tambahkan 3 tetes reagen siklamat 2 dan dihomogenkan.

4) Tambahkan 3 tetes reagen siklamat 3 , dan dihomogenkan.

5) Amati perubahan yang terbentuk.

\section{Analisis Data}

Analisis data pada uji kualitatif zat pemanis buatan sakarin dan siklamat pada minuman bubble drink yang dijual di kota Surakarta adalah analisis data dengan pendekatan analisis induksi. Dimana peneliti menyangkal atau mengkonformasi hipotesis berdasarkan hasil uji kualitatif di lapangan. 


\section{Hasil dan Pembahasan}

Hasil uji kualitatif pada 25 sampel bubble drink untuk sakarin : tidak terbentuk flouresensi hijau dan uji kualitatif siklamat : tidak terbentuk endapan putih. Sehingga dapat ditarik kesimpulan 25 sampel bubble drink di kota Surakarta yang diperiksa tidak mengandung kedua pemanis buatan yaitu sakarin dan siklamat.

Tabel I. Hasil Uji Kualitatif Pemanis Buatan Sakarin dan Siklamat.

\begin{tabular}{|c|c|c|c|c|}
\hline \multirow{2}{*}{ No } & \multirow{2}{*}{ Kode } & \multirow{2}{*}{$\begin{array}{c}\text { Hasil } \\
\text { Pengamatan }\end{array}$} & \multicolumn{2}{|c|}{ Hasil Uji Pemanis } \\
\hline & & & Sakarin & Siklamat \\
\hline 1 & A1 & TAP & negatif & negatif \\
\hline 2 & A2 & TAP & negatif & negatif \\
\hline 3 & A3 & TAP & negatif & negatif \\
\hline 4 & A4 & TAP & negatif & negatif \\
\hline 5 & A5 & TAP & negatif & negatif \\
\hline 6 & B1 & TAP & negatif & negatif \\
\hline 7 & B2 & TAP & negatif & negatif \\
\hline 8 & B3 & TAP & negatif & negatif \\
\hline 9 & B4 & TAP & negatif & negatif \\
\hline 10 & B5 & TAP & negatif & negatif \\
\hline 11 & $\mathrm{C} 1$ & TAP & negatif & negatif \\
\hline 12 & $\mathrm{C} 2$ & TAP & negatif & negatif \\
\hline 13 & C3 & TAP & negatif & negatif \\
\hline 14 & $\mathrm{C} 4$ & TAP & negatif & negatif \\
\hline 15 & $\mathrm{C} 5$ & TAP & negatif & negatif \\
\hline 16 & D1 & TAP & negatif & negatif \\
\hline 17 & D2 & TAP & negatif & negatif \\
\hline 18 & D3 & TAP & negatif & negatif \\
\hline 19 & D4 & TAP & negatif & negatif \\
\hline 20 & D5 & TAP & negatif & negatif \\
\hline 21 & E1 & TAP & negatif & negatif \\
\hline 22 & $\mathrm{E} 2$ & TAP & negatif & negatif \\
\hline 23 & E3 & TAP & negatif & negatif \\
\hline 24 & E4 & TAP & negatif & negatif \\
\hline 25 & E5 & TAP & negatif & negatif \\
\hline 26 & K1 & $\begin{array}{l}\text { Warna hijau } \\
\text { fluoresensi }\end{array}$ & positif & negatif \\
\hline 27 & $\mathrm{~K} 2$ & $\begin{array}{l}\text { Endapan } \\
\text { putih }\end{array}$ & negatif & positif \\
\hline 28 & K3 & TAP & negatif & negatif \\
\hline 29 & K4 & TAP & negatif & negatif \\
\hline
\end{tabular}

Keterangan:

Kode A : Bubble drink yang dijual di kecamatan Banjarsari

Kode B : Bubble drink yang dijual di kecamatan Jebres

Kode C : Bubble drink yang dijual di kecamatan Laweyan.

Kode D: Bubble drink yang dijual di kecamatan Serengan.

Kode E : Bubble drink yang dijual di kecamatan Pasar Kliwon.

Kode K1 : Kontrol positif sakarin

Kode K2 : Kontrol positif siklamat

Kode K3 : Kontrol negatif sakarin

Kode K4 : Kontrol negative siklamat

TAP : Tidak ada perubahan

Pada hasil uji kualitatif sampel sakarin menggunakan rapid test kit pemanis sakarin tidak menunjukkan perubahan (tidak terbentuk warna hijau fluoresensi), sehingga dapat disimpulkan bahwa hasil uji kualitatif sakarin negatif. Hasil uji kualitatif sampel siklamat menggunakan rapid test kit pemanis siklamat tidak menunjukkan perubahan (tidak terbentuk endapan putih), sehingga dapat disimpulkan bahwa hasil uji kualitatif siklamat negatif.

Hasil negatif dapat disebabkan karena rendahnya pengetahuan penjual minuman tentang pemanis buatan. Penjual tidak mengetahui takaran yang tepat dalam penambahan pemanis buatan seperti sakarin dan siklamat ke dalam bubble drink agar tidak menyebabkan gangguan kesehatan.(Ardiarini \& Gunanti, 2004).

Takaran yang tepat untuk penambahan pemanis buatan disesuaikan dengan ADI (Acceptable Daily Intake). ADI adalah jumlah maksimum bahan tambahan pangan dalam miligram per kilogram berat badan yang dapat dikonsumsi setiap hari selama hidup tanpa menimbulkan efek merugikan terhadap kesehatan. ADI untuk pemanis buatan sakarin adalah $0-5 \mathrm{mg} / \mathrm{kg}$ berat badan. ADI untuk pemanis buatan siklamat adalah $0-11 \mathrm{mg} / \mathrm{kg}$ berat badan.(BPOM).

Jika kita mengkonsumsi sakarin melebihi ADI, maka dapat menimbulkan berbagai macam risiko kesehatan seperti tumor, dan kanker. Konsumsi siklamat melebihi ADI juga dapat berisiko menimbulkan iritasi, asma, hipertensi, diare, sakit perut, alergi, impotensi, gangguan seksual, kebotakan, dan kanker otak. 
Selain itu, sakarin mempuyai rasa manis dan sedikit pahit (Handayani), sehingga penambahan sakarin juga dapat mempengaruhi cita rasa dari bubble tea, maka dari itu penjual enggan menggunakan sakarin sebagai pemanis dalam bubble tea. Penggunaan susu kental manis sebagai salah satu tambahan komposisi bubble tea menjadi pertimbangan penjual untuk tidak menambahkan sakarin dan atau siklamat ke dalam bubble tea, karena susu kental manis sudah mampu memberikan rasa manis dan mengandung kadar glukosa yang tinggi (Tea, 2014).

Pada komposisi utama bubble tea, yang berupa bubble yang berasal olahan tepung tapioca, sudah ditambahkan gula pada proses pembuatannya(Hirao \& Takahashi, 1990). Bublle berasa manis, sehingga dirasa tidak perlu ditambahkan pemanis buatan pada minuman bubble tea.

Pembelian reagen rapid test kit pemanis sakarin dan siklamat, tidak disertakan komposisinya. Maka dari itu kami menyesuaikan dengan acuan dari beberapa penelitian dengan interpretasi hasil yang sama. Reagen rapid test kit pemanis sakarin diduga mengandung komposisi $\mathrm{H}_{2} \mathrm{SO}_{4}$, resorsinol, dan $\mathrm{NaOH}$ karena hasil positif ditunjukkan dengan warna hijau fluoresensi. (Tahir \& Vitrianty, 2013). Penambahan $\mathrm{H}_{2} \mathrm{SO}_{4}$ dilakukan dengan tujuan untuk membentuk obenzoatsulfonamida seperti tersaji pada gambar 3.

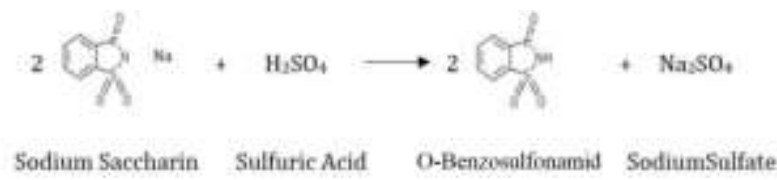

\section{Gambar 3. Reaksi Natrium Sakarin dengan $\mathrm{H}_{2} \mathrm{SO}_{4}$}

(Http://environmentclearance.nic.in)

Pada reagen rapid test kit pemanis siklamat diduga mengandung $\mathrm{BaCl}_{2}$, karena interpretasi hasil menunjukkan terbentuknya endapan $\mathrm{BaSO}_{4}$ (endapan putih) sesuai dengan penelitian Hanyani tahun 2015. (Handayani \& Agustina, 2015). Mekanisme reaksi antara natrium siklamat dengan $\mathrm{BaCl}$ hingga terbentuknya endapan $\mathrm{BaSO}_{4}$ berwarna putih tersaji pada gambar 3

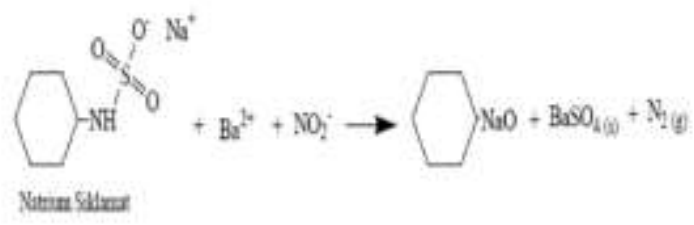

\author{
Gambar 4. Reaksi Natrium Siklamat \\ dengan $\mathrm{Ba}^{2+}$
}

(Marliza dkk., 2019)

\section{Simpulan}

Tidak ditemukan zat pemanis sakarin dan siklamat pada 25 minuman bubble drink yang dijual di kota Surakarta. Penjual tidak menambahkan sakarin dan siklamat, karena rasa manis sudah didapatkan dari susu kental manis dan bubble, selain itu penambahan pemanis buatan sakarin dan siklamat dapat mempengaruhi cita rasa dari bubble tea.

\section{Ucapan Terima Kasih}

Terima kasih kami ucapkan kepada LPPM STIKES Nasional atas bantuan yang diberikan dalam menyelesaikan penelitian ini.

\section{Daftar Pustaka}

Ardiarini, O., \& Gunanti, I. R. (2004). Kajian Keamanan Pangan Ditinjau dari Kandungan Pewarna Sintetis dan Pemanis Buatan dalam Minuman Jajanan (Studi pada Sdn Dukuh Menanggal Ii/425 Gayungan Surabaya). Buletin Penelitian Sistem Kesehatan, 7(1), 21103.

BPOM, R. (2014). Peraturan Kepala Badan Pengawas Obat Dan Makanan Republik Indonesia Nomor 4 Tahun 2014 Tentang Batas Maksimum Penggunaan Bahan Bahan Tambahan Pangan Pemanis. Jakarata: BPOM, $1-$ 63.

Das Neves, A. O. C., Melo, T. A., Nunes, M. B., \& Romano, C. C. (2020). Effect of saccharin sodium and the sodium cyclamate on human cells treated with lactobacillus plantarum lp62. Food \& Nutrition Journal.

Handayani, T., \& Agustina, A. (2015). Penetapan kadar pemanis buatan (Na-siklamat) pada minuman serbuk 
instan dengan metode alkalimetri. Jurnal Farmasi Sains dan Praktis, 1(1), 1-6.

Hirao, K., \& Takahashi, S. (1990). Effects of the addition of sugar to tapioca pearls. Journal of Home Economics of Japan, 41(2), 123-132.

Http:/ / environmentclearance.nic.in/writerea ddata/FormB/TOR/Additional_Att achments/02_Jan_2019_1110095.

Diakses pada 5 Juni 2020

Http://www.labsteskit.com.Diakses pada 25 Mei 2020.

Lestari, D. (2011). Analisis Adanya Kandungan Pemanis Buatan (Sakarin dan Siklamat) pada Jamu Gendong di Pasar Gubug Grobogan. Jurnal Giz̨i dan Pangan, 10(3), 44-47.

Marliza, H., Mayefis, D., \& Islamiati, R. (2019). Analisis Kualitatif Sakarin dan Silamat pada Es Doger di Kota Batam. JURNAL FARMASI DAN ILMU KEFARMASLAN INDONESLA, 6(2), 81-84.
Ramadhani, N., Herlina, H., \& Utama, A. J. F. (2018). Penetapan Kadar Natrium Siklamat Pada Minuman Ringan Kemasan Dengan Menggunakan Metode Spektrofotometri UV. Jurnal Mandala Pharmacon Indonesia, 4(1), 712.

Tahir, I. A. C., \& Vitrianty, V. (2013). ANALISIS KANDUNGAN PEMANIS BUATAN PADA SARI BUAH MARKISA PRODUKSI MAKASSAR. As-Syifaa Jurnal Farmasi, 5(2), 185-191.

Tea, B. (2014). Bubble Tea Toppings. Teaching Science In Culturally Relevant Ways: Ideas From Singapore Teachers, 35.

Uçar, A., \& Yilmaz, S. (2015). Saccharin genotoxicity and carcinogenicity: A review. Adv. Food Sci, 37, 138-142.

Winarno, F. (1997). Food chemistry and nutrition. Gramedia Pustaka Utama Ltd., Jakarta. 